\title{
El Arzobispo Lorenzana
}

ante la problemática de los

derechos parroquiales y el

arancel de 1767

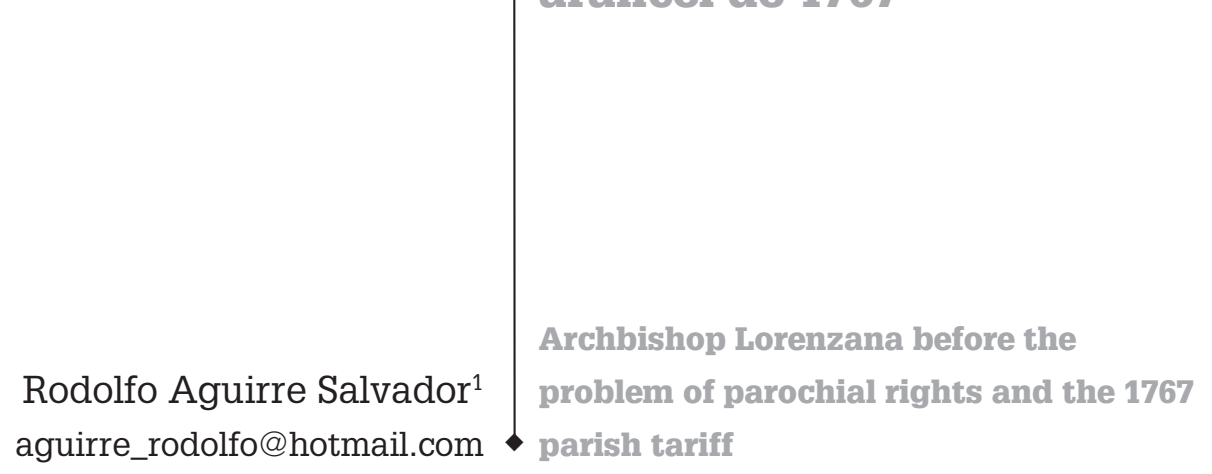

\section{Resumen}

En este trabajo se analiza el arancel de 1767, su aplicación en los curatos del arzobispado de México y las discusiones del cuarto concilio mexicano. Para ello se consultaron diferentes fuentes que reflejan los problemas sobre el pago de derechos parroquiales y la política eclesiástica vi- gente. El eje ha sido el papel del arzobispo de México Lorenzana, quien estuvo en el centro de las polémicas desatadas. El objetivo es contribuir con más elementos de análisis a la discusión sobre los alcances y los límites del reformismo eclesiástico, acudiendo a la cuestión de las parroquias y su régimen de pagos.

Palabras clave: arancel de obvenciones, arzobispo Lorenzana, cuarto concilio mexicano, reforma parroquial.

\section{Abstract}

In this paper we analyze the 1767 tariff, its application in the parishes of the archbishopric of Mexico and the discussions of the Fourth Mexican Council. For this, different sources that reflect the problems on the payment of parochial rights and the ecclesiastical policy in force were consulted.
Lorenzana, the Archbishop of Mexico, was the axis of that movement and the center of the unleashed controversies. The objective of this article is to contribute with some more elements of analysis on the scope and limits of the ecclesiastical reformism, regarding the situation of the parishes and their payment system.

Key words: parish tariff, Archbishop Lorenzana, fourth Mexican council, parochial reform.

1 Universidad Nacional Autónoma de México, Instituto de Investigaciones sobre la Universidad y la Educación, México.

Centro Cultural Universitario, Ciudad Universitaria, C.P. 04510, Coyoacán, Ciudad de México, México. 
El arzobispo Francisco Antonio de Lorenzana ha sido definido en la historiografía como un modelo de prelado ilustrado que apoyó e instrumentó la política reformista de Carlos III en la Iglesia novohispana. ${ }^{2}$ Aunque es evidente su actuación en favor de los intereses reales en asuntos tan cruciales como la expulsión de los jesuitas, la realización del cuarto concilio provincial mexicano, el proyecto de reforma de la religiosidad popular o la reorganización parroquial en la ciudad de México (García Ayluardo, 2010; Mazín, 1989, y Sánchez Santiró, 2004), no obstante, se conoce poco su papel en otros problemas menos destacados, pero también importantes, y donde el arzobispo no fue tan radical ni reformador. Uno de ellos fue el de los derechos que los fieles pagaban a sus curas por diferentes ministerios espirituales. Carlos III ordenó revisar el asunto de los excesos de los curas y tomar medidas concretas al respecto. El asunto ya venía discutiéndose desde al menos la década de 1740 como parte de los planes para la reforma del clero en Indias (Aguirre Salvador, 2008, y Álvarez Icaza, 2016).

La cuestión de las obvenciones no tuvo una solución fácil debido a todos los intereses involucrados, no sólo de párrocos y fieles, sino también los del alto clero e incluso de la real hacienda. Ello porque desde el siglo XVI se había decidido que el sustento de los curatos debía recaer, fundamentalmente, en los mismos fieles, liberando a la real hacienda de esa obligación. Además, aunque formalmente se destinó parte del diezmo para las parroquias, en los hechos el alto clero novohispano pospuso indefinidamente ese reparto bajo la justificante de que esos fondos apenas alcanzaban para las catedrales (Aguirre Salvador, 2014, pp. 9-44).

Igualmente, el contexto de la segunda mitad del siglo XVIII pesó mucho en el tratamiento que el arzobispo de México le dio al asunto. Primero, porque se daba en una etapa de serios intentos por transformar a la Iglesia, sus corporaciones y su relación con la monarquía y la sociedad. En épocas anteriores, el asunto de los derechos parroquiales fue considerado sólo del ámbito episcopal y no tanto de la Corona. Sin embargo, bajo Carlos III se convirtió en parte del cambio que deseaba lograrse en la relación de los curas con los fieles; es decir, terminar con los "abusos" de esos ministros en las obvenciones. Ahora, la Corona misma y sus instancias directas, como las audiencias y los tribunales, se involucraron y se convirtieron en árbitros, desplazando hasta cierto punto a los tribunales eclesiásticos. Un interesante balance reciente sobre el papel político de Lorenzana y su ambivalente relación con el alto clero novohispano es el de I. Escamilla González (2005). Véanse también D. A. Brading (1993) y W. B. Taylor (1999).

Letras Históricas / Número 18 / Primavera-verano 2018 / México / pp. 37-61 / ISSN: 2448-8372 
Segundo, porque el cambio parroquial a raíz de la secularización de doctrinas y el arribo de curas seculares en sustitución de los frailes era una coyuntura poco propicia para intentar imponer un arancel único en el arzobispado. Sobre esta transición sabemos poco aún, más allá del proceso de traspaso de un clero a otro. El hecho es que el arancel de Lorenzana salió a relucir con fuerza en el proceso de reacomodo de curas, parroquias y comunidades de fieles ante el nuevo escenario que les presentó ese proceso. $^{3}$

Y tercero, porque en las sesiones del cuarto Concilio provincial mexicano de 1771, los obispos asistentes defendieron con énfasis la conservación del status quo del régimen de derechos parroquiales de cada diócesis ante la insistencia del representante del rey, el fiscal Rivadeneira, por imponer un cambio de fondo. Aunque todos coincidían en que el régimen de obvenciones debía ser equitativo, tanto para los curas como para los fieles, el problema estribaba en consensar qué era lo justo precisamente. Los debates en ese concilio giraron en torno a la viabilidad de imponer o no un solo arancel de obvenciones parroquiales para Nueva España, en respuesta al mandato del Tomo Regio de Carlos III. Según éste, debía acabarse con la diversidad de pagos y los abusos de los curas y establecer la uniformidad. En las discusiones salieron a relucir las diferencias entre las prácticas de cada diócesis, entre los obispos y el asistente real; se evidenció el interés de los mitrados por conservar el status quo. Al final, no hubo una reforma sino un reforzamiento del régimen que había funcionado hasta entonces, así como la insistencia al fiscal Rivadeneira de que se necesitaba más tiempo para consensar y hallar una solución adecuada que satisficiera a todas las partes.

En las siguientes páginas se analizan el establecimiento del arancel de 1767 y las discusiones en el IV Concilio, y se expone una primera aproximación a los resultados y sus efectos en los curatos, tomando de ejemplo el arzobispado de México. El objetivo es abonar a la discusión sobre los alcances y los límites del reformismo eclesiástico acudiendo al terreno de las parroquias y su régimen de obvenciones.

\section{El régimen de derechos parroquiales del III Concilio Mexicano}

En el tercer Concilio provincial mexicano de 1585 se establecieron las directrices básicas en materia de derechos parroquiales para las diócesis

3 Taylor (1999, p. 638) ya ha señalado acertadamente que el arancel de 1767 fue usado como "arma" o pretexto de los pueblos contra los curas. 
novohispanas. La discusión estuvo centrada en cómo fijar ingresos para el sustento de los curas sin comprometer los intereses del alto clero o de la Corona. Según las obligaciones del Real Patronato, la Corona debía sustentar las necesidades de la Iglesia en el Nuevo Mundo, lo cual se esperaba cumplir con los diezmos que Roma le concedió (Rubial, 2013, pp. 88-89). Sin embargo, estos recursos se destinaron desde el principio a los obispos y a los cabildos catedralicios, quedando por definir si eventualmente los curas participarían también de esos fondos, como sucedía en varios obispados de la península ibérica. Paralelamente, se buscó que los encomenderos mantuvieran a los curas de sus indios tributarios; mas con la decadencia de la encomienda y el traspaso de los pueblos a la Corona, volvió a recaer en el rey la obligación. Éste decidió que de la real hacienda se pagara un salario a los curas, conocido como sínodo real, cuyo monto fue por entonces de 100 pesos y 50 fanegas de maíz (Gibson, 1989, pp. 101-137).

A la vez que creció la red de doctrinas y curatos en cada obispado, en el siglo XVI, se buscaron varias soluciones para su manutención. En varios memoriales del Tercer Concilio Mexicano se pidió el establecimiento de parroquias uniformes en número de fieles y de curas, en lograr del rey un salario suficiente para que los curas no tuvieran que cobrar a los fieles y que los indios sólo aportaran sus alimentos. No se insistió ya en la cuestión del diezmo o del tributo, pues en años recientes se había dejado en claro que de ahí no saldría nada. Para los obispos era muy importante resolver la cuestión, pues el fortalecimiento de las catedrales dependía también de parroquias consolidadas que apoyaran la autoridad episcopal en el territorio diocesano.

La solución del Tercer Concilio Mexicano para asegurar el sustento del clero parroquial no incluyó el diezmo, ni el tributo real, ni recursos de la real hacienda más allá del sínodo real, sino un régimen inspirado en las doctrinas de los frailes, el cual consistía en obtener de los fieles limosnas, ofrendas y servicios personales garantizados por los caciques y las cajas de comunidad en el caso de los pueblos de indios, así como de los fieles en el resto de los partidos. Un punto crucial de ese régimen fue la discrecionalidad otorgada a los obispos para decidir en cada diócesis la mejor solución. Pero es importante advertir que ese modelo se inspiró en las tendencias que en los hechos ya se venían practicando en décadas recientes y que los obispos no hacían sino aceptarlas y regularlas en el tercer Concilio (Aguirre Salvador, 2014, pp. 9-44).

La continuación de muchas doctrinas de indios bajo la administración de los frailes, según real cédula de 1585, complicó a los obispos el poder regular los derechos parroquiales mediante un arancel general. La polí- 
tica que se impuso entonces fue dar libertad a curas y fieles para lograr acuerdos y consensos locales. Así, después del tercer Concilio, en cada obispado se practicaron diferentes arreglos, independientemente o no de que los obispos establecieran aranceles como un referente en caso de diferencias en las parroquias.

No faltaron épocas en que las controversias entre curas y fieles aumentaron y los arzobispos intentaron imponer un arancel general. En 1638 se elaboró uno, ${ }^{4}$ el cual siguió citándose hasta el siglo XVIII. Este decreto estableció los montos a pagar de casamientos, entierros y, en alguna medida, los de fiestas patronales o de santos, pero nada sobre celebraciones de cofradías o de haciendas, que llegaron a ser otro renglón de los ingresos parroquiales desde fines del siglo XVII; tampoco se estipuló algo sobre primicias de cosechas, raciones semanales o salarios. El pago por bautismos era voluntario, así como las ofrendas de los fieles. Es presumible que conforme aumentaron los tipos de derechos, curas y fieles establecieron diferentes acuerdos, pagos en especie y servicios personales que se volvieron costumbre.

El arzobispo Francisco de Aguiar y Seixas intentó imponer ese arancel durante sus visitas pastorales en la década de $1680 .{ }^{5}$ No sabemos aún hasta qué punto se obedeció esta orden, pero no parece que así fuera generalmente, a juzgar por las visitas pastorales entre 1715 y 1722 del arzobispo Lanciego Eguilaz, quien insistió a los curas y a las comunidades que cumplieran con la orden de su antecesor (Aguirre Salvador, 2016). Estos intentos de ambos arzobispos dejan en claro que ni ellos podían imponer un arancel fijo de obvenciones, debido a que la normativa conciliar vigente permitía los arreglos locales y que los pueblos eran conscientes de ello.

No obstante, el arancel de 1638, con algunos cambios, siguió siendo un referente hasta el establecido por el arzobispo Lorenzana en 1767, en el sentido de que se tomaba como parámetro para consensar acuerdos. Los conflictos generalmente se debían al incumplimiento de convenios locales más que del arancel. De esa forma, hasta 1767 lo que dominó fueron esos acuerdos locales, interrumpidos de vez en vez por pleitos (Taylor, 1999, p. 634 y Aguirre Salvador, 2015), así como por curas nuevos deseosos de cambios, actitud esta última magnificada por funcionarios $\mathrm{y}$ detractores del clero.

4

AGN, Civil, 2141, exp. 1. Real provisión para que se obedezca el arancel de derechos parroquiales de 1638 en todos los curatos del arzobispado, de 9 de noviembre de 1741. AHAM, CL19, libro 1, f. 40. En la visita de la doctrina franciscana de Texcoco, por ejemplo, ordenó al doctrinero "que haga guardar y cumplir el arancel que se fijó".

Letras Histórícas / Número 18 / Primavera-verano 2018 / México / pp. 37-61 / ISSN: 2448-8372 
Así, cada generación de feligreses o de curas pudo haber impulsado cambios en los derechos, dependiendo de las condiciones contractuales de cada parroquia, de la estabilidad de su población o su economía, de la fundación de más cofradías ${ }^{6}$ o gravámenes al clero parroquial por parte de la Corona o de la mitra. Muchas veces el cambio del cura titular era aprovechado por una u otra parte para renegociar nuevas tasas, formas o tipos de pago. Todo ello era permitido por las autoridades eclesiásticas y virreinales, confiando en que en cada partido se llegara al consenso de las partes. De no ser así, los funcionarios de la mitra o, en casos extremos, la real audiencia, intervenían para tratar de poner las cosas en orden nuevamente, con o sin arancel de por medio.

\section{El arancel de 1767 y los debates en el IV Concilio sobre obvenciones}

En el mes de julio de 1767 el arzobispo Lorenzana decretó un renovado arancel de derechos parroquiales para su jurisdicción, buscando un nuevo equilibrio entre las necesidades pecuniarias de los curas y la moderación de pagos de los fieles, especialmente los indios, atendiendo a la política monárquica al respecto. Según este prelado, el arancel de 1638 era confuso, intrincado y no servía de regla fija, concepto este último a tono con la política centralista y uniformadora de la Corona.

No obstante, este arancel reglamentaba básicamente lo mismo que el anterior: bautismos, matrimonios, entierros, misas de difuntos y cabo de año, así como entierros de difuntos de haciendas o estancias y las procesiones. ${ }^{7}$ A los indios, además, se les regulaban los diferentes tipos de misas: de las Pascuas, las titulares, de Corpus, domínicas, de las visitas o de las capillas de haciendas. Las misas dominicales oficiadas en las cabeceras parroquiales serían gratuitas, pero no así las de los pueblos de visita, que debían pagarse. Sin embargo había algunas diferencias al reconocer nuevas realidades de las parroquias, tal como la administración en las haciendas y el reconocimiento de varios tipos de fieles: españoles, mestizos, mulatos e indios de pueblo, de cuadrilla o de hacienda. Respecto a las cofradías, el arancel respetaba los convenios pactados entre cofrades y curas, o en las constituciones de las primeras. A fines de siglo XVII se dio la proliferación de cofradías en el arzobispado, que no sólo consolidaron las formas de religiosidad de los pueblos sino también las obvenciones parroquiales (Vetancurt, 1982). Coincido con Taylor (1999, p. 636) en cuanto a que Lorenzana sólo hizo algunos cambios superficiales. 
El arancel de Lorenzana seguía permitiendo ciertos pagos generales, que en algunos pueblos se hacía anualmente, por concepto de bautismos, matrimonios y defunciones, siendo éstos más moderados que los decretados por el arzobispo. Otra novedad era la exención del pago de sepultura en iglesias exentas ${ }^{8}$ y en cementerios comunes, fuera de la iglesia parroquial (Arancel para todos los curas, 1840, f. 24). Este decreto, junto con el del pago de misas dominicales en las visitas, ocasionaría mucho malestar entre los curas. Taylor tiene razón al señalar que esa distinción de pagos que hizo entre cabeceras y visitas provocó trastornos en la vida parroquial (Taylor, p. 636).

Cabe agregar que el arancel en cuestión omitió cualquier referencia a varios pagos que, al menos en el arzobispado de México, realizaban los fieles, tales como la ración semanal, las primicias o la ayuda de vino, cera y aceite, así como las sementeras para la iglesia, por citar las más mencionadas en los informes de los curas, pues había otros derechos específicos en varios curatos (Aguirre Salvador, 2015). Esto demuestra que el decreto reglamentaba pagos de los rubros básicos, pero que en los hechos existían muchos otros. El último decreto del arancel, sin embargo, relativizaba cualquier imposición o regla fija:

Y para que en adelante, ni los curas ni los indios sean sensiblemente perjudicados en los derechos, con pretexto de costumbre, se declara que ésta ha de ser con mutuo consentimiento de párrocos y feligreses, luego que sea publicado este arancel, sin que quede arbitrio a las partes para variar por su voluntad, una vez que hayan consentido en arancel o en costumbre. Francisco, Arzobispo de México (Arancel para todos los curas, 1840, f. 27).

Al final del arancel, el gobierno virreinal y la Corona dieron su visto bueno, esperando el arribo de la regla fija a los derechos parroquiales (Taylor, 1999, p. 637). No obstante, seguían reconociendo la fuerza de la costumbre y la negociación, reforzando la idea de que la primera sólo podría subsistir por consenso entre las partes, y que a falta de éste, el arancel debería prevalecer. Esa posibilidad de conservar la costumbre por sobre el nuevo decreto fue muy importante, porque relativizó el pretendido afán de la regla fija en la práctica. No obstante, los pleitos continuaron.

Contando con este antecedente, se realizó en 1771 el Cuarto Concilio Provincial Mexicano, donde se abordaron diversas cuestiones cruciales

${ }_{8} \quad$ Iglesias y capillas de los pueblos de visitas, fundamentalmente. 
sobre la reforma de la Iglesia novohispana tales como la censura de la doctrina jesuita, la sujeción de la Iglesia a los intereses reales y su independencia de Roma, así como la reforma del clero y de las costumbres de la feligresía (Gonzalbo, 1985, pp. 5-31). En contraste, otras cuestiones recibieron poca atención no obstante que la Corona ordenó un tratamiento atento, como la reorganización de los curatos para lograr, precisamente, la reforma de la vida cristiana de los fieles. Cuatro puntos de la real cédula de 21 de agosto de 1769, que sirvió de directriz principal al Concilio, también conocida como Tomo regio, abordaban directamente la reforma de la vida parroquial, a saber:

IV. Que los párrocos tampoco hagan exacciones indebidas a sus feligreses y se corrija donde todavía subsista el abuso de llevar los curas sínodo a costa del Real Patrimonio en aquellas parroquias que tengan emolumentos y rentas suficientes, por no ser justo gravar indebidamente al erario real, teniendo contra sí tantas cargas de justicia para la administración de ésta y defensa de esas remotas provincias.

VII. Que siendo tan estrecha la obligación de los párrocos a explicar el Evangelio e instruir en los rudimentos de la doctrina cristiana a los fieles, el concilio arregle, con conocimiento de los descuidos que en esto haya, el tiempo y forma en que precisamente se cumpla en los días festivos a lo menos.

XI. Que se dividan las parroquias donde su distancia o número lo pida para la mejor administración de sacramentos de los fieles, arreglando el concilio los medios de ejecutar esto, con intervención del vicepatrono y sin perjuicio del patronazgo real ni del erario, prefiriendo en esta división y cómoda distribución de parroquianos, el bien espiritual de éstos, al interés bursático de los actuales párrocos, y entretanto que esto se formalice, les obliguen los diocesanos a dotar y poner teniente.

xx. Finalmente, se deberán establecer todos los medios de desarraigar ritos idolátricos, supersticiones, falsas creencias, instruyéndose el metropolitano y sufragáneos de lo que pase en sus respectivas diócesis para deliberar en el Concilio provincial, condenando y proscribiendo cuanto sea de esta especie y encargando la instrucción sólida de los fieles en los misterios de nuestra sagrada religión y prácticas de las virtudes y asistencia a las parroquias y divinos oficios, como dispone la Iglesia, excusando en lo posible todo trato duro a los neófitos, edificándoles más bien con el ejemplo y la continua enseñanza, indicando los 
medios prácticos para que los párrocos y demás individuos del clero secular y regular cumplan tan necesaria obligación suya. ${ }^{9}$

El punto IV, el que más nos interesa aquí, era muy general, sin especificar a qué exacciones indebidas se refería. Tampoco menciona nada sobre los aranceles o sobre la participación de los curas en el reparto del diezmo. Por el contrario, el punto insistía en quitar el sínodo real ${ }^{10}$ a los curatos, lo cual se consideraba un abuso en aquéllos con rentas suficientes. Para el régimen de Carlos III, la Corona no tenía obligaciones económicas con los curatos.

Ya en el desarrollo del cuarto Concilio, la idea de la "codicia" de los curas estuvo muy presente. Luego de que un participante del Concilio denunciara que en Michoacán los indios eran persuadidos a bendecir a sus santos cada inicio de año, el autor del Extracto compendioso (1999, p. 316) expresaba: "todos son errores [...] les han dado motivo para que lo crean así sus propios ministros codiciosos, que abusan de su simplicidad con sólo el fin de trasquilarlos". Desde el principio, el asistente real, Antonio de Rivadeneira, impulsó cambios significativos en los obispados, "especialmente sobre puntos públicos, civiles, seculares, benéficos al bien temporal y espiritual de tantos miserables indios, y aun de los infieles y neófitos, y de los conducentes a la jurisdicción real, sus altas regalías y patronato" (Zahino Peñafort, 1999, p. 715). Sin embargo, para marzo de 1771 el asistente expresó al virrey su impaciencia ante la lentitud y la superficialidad con que, desde su punto de vista, los mitrados estaban abordando asuntos centrales de la reforma de la Iglesia, incluyendo

misiones, extinción de congregaciones y cofradías, división de parroquias, doctrinas laxas para su reforma, nuevo catecismo de doctrina, arancel o salarios de los ministros de sus curias, vacantes de capellanías a título de dicho devolutivo que pretenden los obispos, y otros de los contenidos en el Tomo Regio (Zahino Peñafort, 1999, p. 716).

Frente a esta óptica del asistente, los obispos apoyaron la continuidad de las prácticas de cada jurisdicción. ${ }^{11}$ Por ejemplo, uno de los puntos

10 doctrinas pobres. Para la primera mitad del siglo XVIII aún subsistía en algunos partidos del arzobispado de México (Aguirre, 2015, pp. 185-235).

11 En este sentido, no es muy preciso cuando Taylor (1999, p. 637) señala que los obispos, de acuerdo con los deseos de Lorenzana, aplicaron el arancel de 1767, pues en 
concretos que se ventilaron fue si los curas tenían o no la obligación de celebrar las misas dominicales en los pueblos cuando sus habitantes contribuían al pago de ellas. El obispo de Puebla, Fabián y Fuero, opinó que sí la tenían, aunque pidió la opinión de los consultores. Tres asistentes, entre ellos el consultor jurista Miguel Primo de Rivera, opinaron que no, puesto que ese pago no era de limosna por la misa,

sino por parte de la congrua sustentación debida al cura, que no tiene diezmos ni otras rentas, que era la razón en que se había fundado el Señor Metropolitano para concebir su derecho. Todos los demás, a lo que me acuerdo, fueron de dictamen de que una vez que los pueblos contribuían, se les debía aplicar la intención (Extracto compendioso, 1999, p. 319).

El maestrescuela de la catedral de México, Cayetano de Torres, defendió la idea de que si los indios daban dinero por concepto de una misa dominical, debía el cura entonces oficiarla, aun y cuando ello fuera parte también de sus alimentos y sustento de obligación de sus fieles. A su vez, el diputado de Guadalajara expresó que en ese obispado nada de lo anterior se usaba, "porque ni contribuían los indios de los pueblos, ni había en ellos una misa más que cada mes o dos meses; porque lo había mandado el señor obispo" (Extracto Compendioso, 1999, p. 319).

A su vez, el arcediano de Oaxaca expresó que en su obispado se practicaba el sinodático ${ }^{12}$ que estableció don fray Ángel Maldonado a principios del siglo XVIII; es decir, había seis "sinodáticos" anualmente, cada uno consistía en cierto pago que en estas seis ocasiones hacían los indios al cura y constituían la congrua de éste. En cambio, en Yucatán se practicaba, según el arcediano asistente, que los indios pagaran por año entre nueve y medio y diez y medio reales al cura. Los fieles contribuyentes se agrupaban en "mantas", cada manta constaba de cuatro matrimonios, o sea ocho contribuyentes. Y cada manta pagaba diez pesos, por lo que un pueblo con 100 mantas pagaba en conjunto 1000 pesos. Queda claro que cada obispado se regía por costumbres y acuerdos diferentes. ¿Cómo establecer un solo arancel para una Nueva España tan diversa?

el cuarto Concilio es claro que desean conservar las prácticas y costumbres de cada obispado.

En su acepción original, el sinodático era un tributo que los clérigos seculares daban al obispo cuando acudían a algún sínodo; es decir, a una asamblea convocada por el prelado. Al parecer, en Oaxaca el término se usó para ciertos pagos preestablecidos de los indios a sus curas (Diccionario de la Lengua Española, 1984, p. 1246). 
Finalmente prevaleció la opinión del arzobispo Lorenzana, quien sólo alcanzó a proponer que se conociera más sobre los sinodáticos de Oaxaca para su posible aplicación:

El Señor Metropolitano concluyó después de todo que se procurase establecer aquí el sinodático después de Oaxaca, que para ello se encargó al Señor Obispo que procurase en su diócesis la razón de estas diligencias y al Señor Asistente Real que solicitase los autos en la Secretaría de Gobierno. El canon quedó en la obligación de aplicar la misa en la cabecera y se suspendió lo demás (Extracto compendioso, 1999, p. 320).

Una de las principales disputas sobre aranceles tuvo lugar el 12 de julio de 1771, cuando se leyeron los destinados a los indios de Oaxaca y de Yucatán, con el objeto de discutir si convendría extenderlos al resto de los obispados, más por presión del asistente real que por iniciativa de los prelados (Diario del cuarto Concilio, 1999, p. 644). Al exponer el de Oaxa$\mathrm{ca}$, se aclaró que las obvenciones llamadas "sinodáticos", que eran sólo seis al año, no estaban autorizadas por la Real Audiencia, ni menos por el Consejo de Indias (Extracto compendioso, 1999, p. 456). Para Yucatán, el obispo volvió a explicar el método de pagar por mantas, algo único en Nueva España. Ante las desaprobaciones de la Real Audiencia al respecto, los obispos defendieron ambas formas de pago:

Pero los obispos y diputados de estas Iglesias asentaron estar en práctica en sus diócesis unos y otros, y se habló mucho sobre su utilidad a los indios, principalmente por el Obispo de Puebla, que casi lo evidenció, y demostró también evitarse con ellos muchos y grandes inconvenientes, y aunque se pulsaron otros en su práctica, parecieron menores y extrínsecos a la utilidad para los indios (Diario del cuarto Concilio, 1999, p. 664).

No obstante, y dada la diversidad de prácticas regionales, los prelados y el asistente real convinieron en formar una junta "del arcediano, maestrescuela y magistral de México y maestrescuela de Valladolid, que han sido todos curas, para que ejecutándolo y conferenciándolo entre sí, diesen su dictamen e instrucción sobre esto" (Diario del cuarto Concilio, 1999, p. 664).

Una tercera postura fue la del arcediano de México, Cayetano Antonio de Torres, quien insistió en decretar una contribución eclesiástica única a todos los indios de Nueva España y que ésta se extendiera a españoles y castas, pues los primeros, siendo los más pobres pagaban más que los segundos: 
era constante que los curatos de indios son más pingües que los de los españoles y que un curato de dos mil indios es más valioso que el de 6-8 o quizás 10,000 españoles, siendo por otro lado manifiesto que el español, y aun el mulato más pobre, tiene más facultades que el indio más rico. Esto lo hizo evidente con lo que acababa de decir el Magistral Omaña de su curato de San Felipe Ixtlahuaca, que aseguró, le valía 8 000 pesos y que tenía 8000 indios feligreses. Porque de aquí, arguyó, al curato del Sagrario de México, de donde dicho Maestrescuela fue cura interino, y dijo que siendo este curato por lo menos de 80000 feligreses, en que se incluyen todos los grandes caudales de esta ciudad, de las más opulentas del mundo, con todo, en su tiempo sólo valía este gran curato a los cuatro curas cerca de 12000 pesos y 3000 escasos a cada uno (Extracto compendioso, 1999, p. 457).

En el Extracto compendioso (1999) se hacía énfasis en que mientras los españoles sí se resistían a pagar a los curas lo que consideraban un exceso o un abuso, los indios, pusilánimes, miserables y rústicos, no:

les pelan toda la lana, precisándolos a varias contribuciones semanarias, mensuales y anuales, obligándolos a que hagan las fiestas que no quieren y a que las pagaran según se las tasen, forzándolos a que sus personas sirvan de fondos y raíces para fundar las cofradías que quieren los curas y cosas semejantes, y después de todo esto, llevándoles a sus obvenciones de bautismos, entierros y casamientos (Extracto compendioso, 1999, p. 457).

En otras palabras, los españoles sólo pagaban por servicios prestados por sus curas, al igual que las castas, y no otra cosa. Sin embargo, expresaba que si todos los fieles estaban obligados a mantener a sus curas, con más razón los españoles, que tenían más recursos que los indios.

Sin embargo, el obispo de Puebla, Fabián y Fuero, defendió esa diferencia de tasas entre indios y españoles aludiendo al rancio problema del diezmo de los naturales: "El Señor de Puebla dijo que como los indios no pagan diezmos, sería razón que pagasen esto a los curas, aun en el caso de que no obvencionen bautizando, etcétera, y lo mismo dijo el Señor Omaña" (Extracto compendioso, 1999 p. 458). Es interesante constatar cómo aún en el siglo XVIII algunos obispos cuestionaban la exención del diezmo a los indios. El autor del Extracto compendioso anota: "Pero éste por cierto es lindo chiste: tampoco pagan diezmo los ricos mercaderes, tenderos, empleados y casi todos los feligreses del Sagrario de México" 
(Extracto compendioso, 1999 p. 457), para luego ironizar sobre las repercusiones históricas de esa exención a los indios:

¿Hay más razón que porque son pobres y miserables y se consideró que esta carga les sería muy gravosa? Pues si porque no pagan diezmos se la hace pagar a los curas lo que no pagan los españoles y demás castas, ¿en qué logran el remedio de su pobreza e infelicidad? Sería esto aliviarlos con una mano y oprimirlos con otra (Extracto compendioso, 1999, p. 457).

Esta idea de igualar el abanico de obvenciones entre indios, españoles y castas mediante contribuciones únicas era realmente innovadora, pero políticamente inviable. Al final, los obispos impusieron que la propuesta fuera revisada también por la junta.

El 17 de julio, el asistente real Rivadeneira interrumpió una exposición del arzobispo Lorenzana para discutir más el punto del Tomo regio sobre exacciones indebidas de los curas (Diario del cuarto Concilio, 1999, p. 669). Los obispos insistieron que ello se resolvería con los aranceles. Así, el arzobispo Lorenzana defendió el suyo, señalando que había comenzado a aplicarse en su jurisdicción y que, desde su punto de vista, estaba terminando con muchos abusos de los curas y que aunque había pueblos que seguían prefiriendo "la costumbre", acudían a la Real Audiencia para suprimir los servicios personales ${ }^{13}$ (Extracto compendioso, 1999, p. 419). Lo que no explicaba el arzobispo al asistente real es que en realidad el arancel se usaba más como un acicate para que los fieles demandaran a los curas, ante la Real Audiencia, una reducción de tipos y tasas de derechos. ¿Fue ese otro propósito del arancel no declarado?

En este sentido, se señalaba en el mismo Extracto compendioso (p. 419) que ese arancel y las divisiones de curatos realizadas habían ocasionado la miseria de éstos, por lo cual cuestionó que ahora, en el concilio, Lorenzana defendiera a los fieles para que los curas cumplieran con sus obligaciones. Independientemente del nivel de certeza de esa aseveración, hay que preguntarse sobre cuántos más miembros del alto clero compartían esta visión del autor del Extracto. Es muy probable que este mismo sector defendiera la conservación de curatos grandes; es decir, con muchos pueblos de visitas, para mantener un nivel promedio de contribuciones de los fieles, por un lado, y para asegurar una congrua suficiente a los ministros, por el otro.

\footnotetext{
13 “El Señor Metropolitano dijo que aquí les iba bien con el arancel y que a los que querían costumbre, era quitándoles el servicio personal, que era parte de ella, y que de este modo salían las provisiones de la Audiencia" (Extracto compendioso, 1999, p. 419).
} 
En otra sesión conciliar, el asistente real promovió la desaparición de los sínodos reales de curatos, a lo cual los obispos le contestaron que ni en el arzobispado ni en Puebla, Oaxaca y Yucatán, y tal vez tampoco en Michoacán y Guadalajara, se pagaba alguno (Extracto compendioso, 1999, p. 465). En esta coyuntura, el representante de la diócesis de Guadalajara aprovechó para demandar, como era la tónica en los mitrados, hacer cumplir a los fieles sus obligaciones económicas con sus curatos, pues, específicamente en la nueva colonia de Santander, "ni pagaban diezmos ni reconocían prelado alguno, contra lo mandado sobre esto último por real cédula del año de 64" (Diario del cuarto Concilio, 1999, p. 669). Agregaba que ahí las supuestas misiones de indios en realidad estaban pobladas por españoles y mulatos, y por ello el teniente Fernando Palacio quitó los sínodos y repartió la jurisdicción eclesiástica de toda la región entre las diócesis de México, Valladolid y Guadalajara.

A pesar del rechazo de los obispos, el asistente real insistió en arrancarles un reparto del diezmo a favor de los curatos, para mejorar su administración espiritual sin afectar a los fieles o a la real hacienda; en concreto, propuso que del diezmo de catedrales se pagara a aquellos curas sin congrua suficiente. Los obispos cerraron filas y defendieron la idea sobre la decadencia de los diezmos, por lo cual era improcedente ayudar de ahí a los curatos, pues antes hacía falta aumentar las prebendas (Extracto compendioso, 1999, p. 466). El arcediano de México remató al expresar que ni un cura de la parroquia de la Santa Veracruz ni los de Puebla, en épocas anteriores, habían obtenido cédula a su favor sobre el diezmo. El mensaje del episcopado a la Corona fue claro: nada del diezmo saldría para el bajo clero.

Ante esta férrea oposición, el asistente real "se contentó por pedir se le diese apunte de si aún se pagaba algún sínodo y si había fundados algunos de aquellos beneficios o las catedrales socorrían a algunas parroquias" (Diario del cuarto Concilio, 1999, p. 669). Luego, en agosto de 1771, explicó al virrey las dificultades para unificar el pago de derechos parroquiales en los obispados y que el asunto aún estaba por resolverse, prometiendo que él seguiría insistiendo en las sesiones sobre los puntos del Tomo Regio (Zahino Peñafort, 1999, p. 732).

Y en efecto, cuando después se discutió la rebaja en los derechos de los tribunales eclesiásticos, el asistente real insistió que el Tomo Regio no ordenó hacer aranceles sino corregir los abusos, ante lo cual Lorenzana y Fabián y Fuero reafirmaron su postura de que la junta resolvería todo (Extracto compendioso, 1999, p. 485), algo que en la práctica no sucedió. En la versión final del cuarto Concilio, el principal decreto sobre el asunto aquí tratado estableció que 
La observancia de los aranceles de derechos parroquiales y tribunales eclesiásticos ha de ser el principal cuidado de los obispos, y en las diócesis en donde no los hubiere o estuvieren sin observancia, se guardarán los que se formen luego por este Concilio con arreglo al Tomo Regio, leyes y cédulas reales, pues con la confusión y falta de regla resulta mucha libertad en la exacción y una notable y excesiva variedad en todas las diócesis, cuando las diferencias de costumbres y prácticas no pueden cohonestar el exceso en los derechos y dan causa a innumerables pleitos (Zahino Peñafort, 1999, p. 179).

Como es posible apreciar, este decreto seguía privilegiando los aranceles por sobre los convenios locales, subestimando las costumbres y las prácticas. El arancel debía fijarse en la iglesia a la vista de los fieles, así como los de las misas y los aniversarios que el cura debería celebrar (Zahino Peñafort, 1999, p. 260). El episcopado novohispano seguía defendiendo formalmente la supremacía de los aranceles para desterrar "la costumbre". Me parece que un decreto así era lo que deseaban que el rey leyera, por más que estuviera distante de la diversidad de prácticas novohispanas. También es de destacar los conceptos de "confusión" y "falta de regla" en la variedad de derechos parroquiales, lo cual pudo estar reflejando la incapacidad de los obispos y sus provisores para cambiar un régimen histórico de obvenciones basado en múltiples convenios locales.

En la cotidianeidad, cada cura sabía los pactos locales, resultado de las condiciones de cada partido y de las negociaciones con cada feligresía, esquema planteado y permitido desde el Tercer Concilio Mexicano. Por supuesto, no creemos que los conciliares hayan ignorado esta realidad, pero reconocerlo abiertamente en el Concilio iba contra la tendencia del Tomo Regio. En cambio, era más conveniente, ante la Corona, reafirmar la utopía de la fuerza de los aranceles y la regla fija.

En otro decreto se privilegiaba la aplicación del arancel en los curatos y se prohibía a los curas establecer más fiestas de las estipuladas en el Concilio. Un decreto más ordenó a los doctrineros ajustarse a los aranceles diocesanos (Zahino Peñafort, 1999, p. 191). Por supuesto que esto también se alejaba de lo que históricamente se había practicado en las doctrinas del arzobispado (Aguirre Salvador, 2015). Igualmente, como extensión del arancel de Lorenzana de 1767, se permitía a los fieles de las visitas enterrar y bautizar a sus parientes en ellas, sin tener que pagar derechos a las cabeceras:

Los ministros de la Iglesia deben apartarse del vicio de la avaricia y aun, según el Apóstol, de toda especie de ella, y así se abstendrán de 
pedir a los indios cosa alguna más que los derechos y emolumentos que por arancel les están señalados [...] En los pueblos de domínica o de visita no introducirán celebración de fiestas más que las mandadas por la Santa Madre Iglesia [...] no precisándoles a que vayan a enterrar los difuntos a la cabecera o a los bautismos en ella, pues por sí o por sus vicarios debe atender a los anexos y darles todo el pasto espiritual, hacer las fiestas que se pidan en cada pueblo y no introducir por codicia otras nuevas (Zahino Peñafort, 1999, p. 186).

No obstante, otro decreto reconocía la existencia de los dos esquemas de derechos: por costumbre o por arancel ${ }^{14}$ (Zahino Peñafort, 1999, p. 187). De hecho, el decreto que obligaba a los doctrineros a sujetarse al arancel de su diócesis también reconocía la existencia de ese doble régimen $^{15}$ (Zahino Peñafort, 1999, p. 191).

Era claro que los deseos de la Corona, expresados a través del asistente real en las reuniones conciliares, de establecer un solo arancel para todas las diócesis, acabar con los convenios locales y destinar parte del diezmo para los curas no tuvieron acogida en los decretos resultantes. Por el contrario, en éstos se reiteró el régimen de autosustento de los curatos, los pagos de los fieles a sus curas o su exención, como el de los entierros de pobres: "es muy propio de la caridad cristiana, y oficio de los párrocos, que cuando muriese algún pobre que no dejase bienes se le dé sepultura sin derechos" (Zahino Peñafort, 1999, p. 216). Otro decreto insistía a los curas privilegiar su caridad y obligación pastoral por sobre sus intereses materiales ${ }^{16}$ (Zahino Peñafort, 1999, p. 216).

14$$
\text { p }
$$
párrocos en sus partidos o distritos que se gobiernen por arancel, tengan caballerías, y que éstas no pasen de dos, a no ser que la administración sea muy dilatada y penosos los caminos, y aun en este caso, también en el de que se gobiernen los curatos por la costumbre, deberán alcanzar licencia del Prelado para poder tener más; y esto se debe entender también de los vicarios" (Zahino Peñafort, 1999, p. 187).

"En las doctrinas de indios reducidos a pueblo que rinden la suficiente manutención a los religiosos según los aranceles de la diócesis o costumbre, se mantendrá sólo el número que sea necesario para que no esté en arbitrio de los prelados regulares erigirlas o calificarlas de conventos, poniendo el número de ocho religiosos, pues ya queda expresado no puede erigirse convento sin expresa licencia real, del vicepatrono y prelado diocesano" (Zahino Peñafort, 1999, p. 191).

16 "En los entierros, aunque sean del más pobre indio, debe ir el párroco o su vicario a hacerlos, revestidos de capa con la cruz y acompañamiento, y aunque sea con los réditos de la renta de la fábrica o de limosnas se pondrán dos luces al cuerpo, y sobre esto 
Para los intereses de los curas, ningún arancel les podía ser conveniente al no contemplar pagos en especie, los cuales podían comercializar para su propio provecho, costumbre que siguió siendo prohibida en el cuarto Concilio ${ }^{17}$ (Zahino Peñafort, 1999, p. 249). A fin de cuentas, puesto que estos decretos nunca fueron oficializados ni se aplicaron, siguieron vigentes los del Tercer Concilio Mexicano de 1585, con lo cual el viejo esquema flexible de derechos parroquiales, diferenciados y negociados, continuó en Nueva España. Un buen ejemplo de ello lo tenemos en la jurisdicción misma del arzobispo Lorenzana y su arancel, el cual fue un modelo para otras diócesis.

\section{La suerte del arancel de Lorenzana en el arzobispado}

En 1772 el arzobispo Lorenzana fue a ocupar la mitra de Toledo, y los decretos del cuarto Concilio quedaron sujetos a la aprobación de Roma, algo que, como es bien sabido, no aconteció. Fueron el arzobispo Alonso Núñez de Haro y los propios curas quienes afrontaron los efectos del arancel de 1767. Los estudiosos del tema han señalado que este nuevo arancel originó varios conflictos entre curas y fieles en el último tercio del siglo XVIII. Taylor, en concreto, ha preguntado: ¿por qué un arancel más bien ordinario, sin grandes innovaciones, provocó tantas disputas? (Taylor, 1995, p. 86 y 1999, p. 636). Zahino Peñafort (1996, p. 78) ha señalado,

encarga este concilio la conciencia de los párrocos y vicarios, pues los miserables indios son cristianos, nuestros prójimos, y debemos darles ejemplo de que la religión católica es suave a todos, y no permitir en caso alguno que los cantores de ellos hagan solos el entierro por huir de que se les estreche a la paga de derechos de entierro. Y la experiencia enseña que cuanto más exaspere un párroco a los indios, tanto más rehúsan éstos pagarle sus emolumentos, aun cuando pueden, y así tenga siempre el primer lugar la caridad, que no les faltara lo temporal” (Zahino Peñafort, 1999, p. 216).

"Para cortar de raíz toda vana interpretación se prohíbe que los clérigos o regulares cultiven por sí los predios o haciendas de la Iglesia, comunidad u obras pías, y manda este concilio que los arrienden a otros o manejen su administración sin distracción de la disciplina monástica, que no se venda por menor la azúcar de sus haciendas en tienda, como también que en los conventos no haya boticas públicas, pues sólo se permiten para el gasto de la comunidad, ni que los curas, con el pretexto de que los indios les paguen sus derechos u otra cosa, hagan comercio de ella, y todo lo que pueda ser indecoroso al estado" (Zahino Peñafort, 1999, p. 249). 
a su vez, que, con o sin arancel, los excesos de los curas y la confusión de pagos continuaron. ${ }^{18}$

Aquí se considera que esos litigios por las obvenciones formaron parte de un proceso más amplio de reajustes en los curatos a raíz de la secularización y la fiscalización de los bienes de comunidad por la Corona. Aunque las autoridades parecían rebasadas ante la diversidad de costumbres y arreglos locales, sin embargo debe pensarse hasta dónde la Corona, el virrey y la mitra querían cambiar ese estado de cosas, o más bien sobrellevar el asunto pero sin intentar cambiar el régimen de distribución de la renta eclesiástica o que la real hacienda aportara más recursos a los curas, como ya se dijo antes. Zahino Peñafort (1996, p. 78) afirma que Lorenzana siguió permitiendo los convenios locales; pero puede dudarse que alguna autoridad pudiera suprimirlos en realidad. No hay que olvidar que tanto el tercer Concilio como el arancel de 1767 permitían esa opción.

Revisar cómo se estaba aplicando este arancel en el arzobispado de México en la década de 1770 nos permite entender mejor la falta de consenso en el cuarto Concilio sobre el proyecto de un arancel único para la Nueva España. Taylor (1999, p. 638) ha señalado que el decreto tarifario de 1767 fue utilizado por los fieles como "un arma" para perseguir sus propios fines e imponerse sobre los curas.

Informes pedidos en 1775 por el sucesor de Lorenzana, el arzobispo Alonso Núñez de Haro y Peralta, a los curas sobre la situación de los fondos de la fábrica parroquial permiten conocer de cerca el grado de aplicación que había tenido el arancel. De entrada se puede apreciar que se había cumplido de forma parcial y en algunos curatos. Aunque en varios de éstos el decreto sí fue aceptado, siempre a voluntad de los pueblos, no obstante fue interpretado de acuerdo a los intereses de los fieles. Había preocupación y molestia de los curas porque los indios entendían que habían sido eximidos del cobro por concepto de sepulturas para el fondo de fábrica (Arancel para todos los curas, 1840, f. 26). Para esos ministros quedaba claro que dicho arancel fue un pretexto para que los fieles intentaran reajustes a la baja del pago de derechos y no sólo los de sepultura, o bien, dejar de prestar antiguos servicios, como lo expresa el cura de

18

Al hablar sobre los abusos de los curas a los indios de sus partidos, la autora reproduce lugares comunes, a saber: "La principal vía para cometer este tipo de abusos era, lógicamente, los llamados derechos parroquiales; así, aunque existía un arancel para toda la archidiócesis, las costumbres locales siempre prevalecían, posibilitando, estipulado por las Leyes de Indias, múltiples conflictos con la feligresía, abusos difíciles de controlar y una confusión generalizada" (Zahino Peñafort, 1996, p. 78). Taylor (1999, p. 635) comparte una idea similar. 
Huizuco: "y aunque, antes del arancel, entre indios y de razón techaban la dicha parroquia, luego que se publicó el arancel se rebelaron a no concurrir con cosa alguna". ${ }^{19}$

En al menos 42 parroquias los vecinos impugnaron el arancel, como en la de Tetepango: "así los de razón como todos los indios no quisieron admitirlo sino a la costumbre, por ser más piadosa". ${ }^{20}$ En los curatos donde sí fue aceptado teóricamente, aproximadamente 68, el decreto fue interpretado de tal manera que en realidad los fieles estaban forzando nuevos convenios. ${ }^{21}$ No sería raro que futuros estudios demostraran que esto era un resultado de que la contaduría de propios y arbitrios les tenía prohibido tomar ahora de sus bienes de comunidad recursos para la parroquia. Un muy inconforme párroco de Teloloapan mostró su descontento ante la mitra preguntando:

¿Qué conexión, qué compatibilidad tiene el arreglo de los derechos parroquiales para que, a título de arancelados, desentendiéndose de todo, no concurran los fieles al culto, veneración y decencia del Santísimo Sacramento? ¿Y el reparo de las iglesias parroquiales? ¿Y el servicio de la sacristía? ¿Y a todo lo demás que con dolor experimentamos?22

En varios pueblos donde se aceptó el arancel, los fieles desconocieron convenios previos de colaboración para los reparos de la iglesia. En San José Malacatepec los indios habían hecho y adornado su iglesia en forma entusiasta incluso. No obstante, en 1774 se arancelaron y dejaron de cooperar, provocando un litigio con su cura ante la Real Audiencia. El ministro espiritual expresó que si se imponían las nuevas condiciones, la parroquia quedaría sólo con pagos de sacramentos y sin derechos fijos. ${ }^{23}$

En la exdoctrina dominica de Oaxtepec, en el valle de Cuernavaca, los fieles usaban del arancel o de la costumbre a su conveniencia, según explicó su cura. ${ }^{24}$ En Ozoloapan, "con el arancel los indios totalmente se han retirado, y así dentro de poco tiempo la santa iglesia se caerá porque ya la sacristía la veo totalmente al caer". ${ }^{25}$ Una excepción fue Tescaliacac, donde no habían pagado fábrica pues se regían por la costumbre, lo cual

\footnotetext{
19 AGN, Bienes Nacionales, 234, exp. 3, f. 182v.

20 AGN, Bienes Nacionales, 234, exp. 3, f. 34v.

21 Taylor (1999) ya había señalado también esta estrategia de los pueblos (p. 642).

$22 \quad$ AGN, Bienes Nacionales, 234, exp. 3, f. 171.

23 AGN, Bienes Nacionales, 234, exp. 3, f. 146v.

$24 \quad$ AGN, Bienes Nacionales, 234, exp. 3, f. 187.

25 AGN, Bienes Nacionales, 234, exp. 3, f. $148 \mathrm{v}$.
} 
cambió con la aceptación del arancel, cuando comenzaron a colaborar con trabajo y materiales. ${ }^{26}$ Esta actitud contrastaba completamente con los fieles del real de minas de Tetela del Río, quienes concluyeron que no debían seguir manteniendo la fábrica parroquial, pues el arancel no lo estipulaba expresamente. Ahí mismo, los pueblos de visita de San Pedro Pesoapan y Tehuehuetla no cuidaban ya de las reses de sus iglesias bajo la misma explicación. Su cura decidió no reclamarles para evitar protestas de todos. ${ }^{27}$

Algunos curatos sólo estaban arancelados de nombre, pues en la práctica seguían con su antigua forma de pagar. En Ocuituco, los tres pueblos de visita eran pobres y aunque se arancelaron, sin embargo seguían obedeciendo a su "costumbre". ${ }^{28} \mathrm{El}$ arancel estimuló, en lo político, intentos de separación de pueblos sujetos, tendencia que no fue mal vista por la autoridad virreinal, pero sí por los curas del arzobispado, pues daba pie a la desintegración parroquial

a causa de que por el mismo arancel, mal entendido, no sólo segregaron aquellas costumbres de servir a la parroquia, sino también se dividieron del gobierno, quedando por superior despacho excepto de este gobernador y república, teniendo cada uno, aun el de Chiapa, que se compone de trece familias, gobernándose en todo por su alcalde y regidores, por cuyo motivo a nada cooperan de lo necesario para esta parroquia. $^{29}$

Otro lamento de los párrocos fue que el arancel exentó del pago de sepulturas a los pueblos de visita. Esta exención fue muy impopular entre los ministros, debido a que la mayoría de los curatos seguía teniendo visitas cuya feligresía en conjunto superaba la de las cabeceras. El cura de Atlacomulco lamentaba esa exención, pues estaba provocando que los templos no tuvieran el mantenimiento necesario, además de que había decaído la atención espiritual. ${ }^{30} \mathrm{La}$ negociación permitida tácitamente en el arancel fue usada por los fieles del curato de Cardonal, donde lograron cambiar el pago en dinero por mano de obra para la fábrica parroquial. ${ }^{31}$

\footnotetext{
26 
Otros espacios parroquiales que comenzaron a causar problemas a los curas fueron los cementerios comunes o simples capillas donde los fieles enterraban a sus difuntos sin pagar ningún derecho de arancel, como en Hueypoxtla. ${ }^{32}$ En Apan sólo los indios de hacienda pagaban alguna obvención. ${ }^{33}$ En algunos otros curatos como Tacuba, Xochimilco o Coyoacán, todos exdoctrinas, sólo la gente de razón pagaba derechos de sepultura.

En otras parroquias el arancel fue aceptado de forma diferenciada, como en Acamistla, donde dos de sus cinco pueblos de visita prefirieron seguir con la costumbre. ${ }^{34}$ Sin embargo, en los tres pueblos que sí se arancelaron, tanto indios como gente de razón se negaron de cualquier modo a pagar la fábrica por sepulturas. Pero en las cabeceras tampoco los curas tenían todo el control. En Teloloapan, barrios enteros se negaban a ayudar a la parroquia, aun arancelada, incluida la gente de razón. ${ }^{35} \mathrm{En}$ Tacuba, los fieles de la vicaría de Popotla se negaron a arancelarse, aun en contra de los deseos del cura. ${ }^{36}$

Algún párroco aprovechó la coyuntura también para desconocer antiguas prestaciones a los fieles. En Temascalcingo, por ejemplo, antes del arancel, los ministros destinaban parte de sus ingresos para reparos de la iglesia, pero luego de 1767, ante la falta de entendimiento con los fieles, suspendieron esa ayuda. ${ }^{37}$ En todo este contexto, un cura de Yecapixtla se aventuró a proponer la desaparición del régimen de pagos de los fieles y que el gobierno se hiciera cargo de mantener a los ministros.

\section{Reflexiones finales}

Los intentos de reforma del régimen de obvenciones parroquiales en las décadas de 1760 y 1770 dan pie para reflexionar sobre los límites de la autoridad para lograr cambios en la Iglesia novohispana. Hemos podido

\footnotetext{
32 éstos en admitir el arancel y del mismo modo ni han pagado antes ni pagan ahora los citados derechos de fábrica; ellos, siempre que su iglesia necesita de algún reparo material, lo hacen a su costo, dan para los gastos de cera para las misas y administran el Viático a los enfermos y para los utensilios de la sacristía y demás que necesita su iglesia, en la que todos se entierran."

37 AGN, Bienes Nacionales, 234, exp. 3, f. 141v.
} 
apreciar cómo la apuesta reformista de la Corona para establecer una solución final y una regla fija para el cobro de derechos tropezó de lleno con un régimen de 200 años que se basaba ante todo en prácticas y convenios específicos de cada diócesis. ¿Cómo podía imponerse un arancel único sobre algo tan arraigado que incluso los obispos defendieron en las reuniones conciliares de 1771 ?

Lorenzana quiso maniobrar para imponer alguna uniformidad, ya fuese su arancel o una práctica más o menos común, como los sinodáticos de Oaxaca, pero no hubo éxito. También es posible que el arzobispo hiciera lo anterior para dar salida a la insistencia del asistente real para que el Concilio decretara una solución de fondo. En los hechos, Lorenzana hubo de aceptar la tendencia común del episcopado novohispano de conservar el régimen vigente de cada obispado, sancionado desde el siglo XVI en el Tercer Concilio Mexicano. Coincido con Escamilla González (2005, p. 141) en cuanto a que era muy complicado hacer coincidir los dictados del Tomo Regio con los de las tradiciones y privilegios de la Iglesia novohispana, pues además las reuniones conciliares se dieron en un ambiente tenso y de confrontación entre el partido del arzobispo, el asistente real y la oposición de una parte de los cabildos catedralicios.

Si bien uno de los principales decretos sobre derechos parroquiales establecía la supremacía de los aranceles, en otros decretos se reconocía la vigencia también de la costumbre y la negociación, como desde el siglo XVI, en el tercer Concilio de 1585. En esta problemática, como en otras, la apuesta reformista de la Corona y del arzobispo no tuvo cabida: cada cura tendría que seguir negociando con sus feligreses el mejor régimen de obvenciones para todos.

Por otro lado, el arancel de 1767 tuvo otras repercusiones quizás inesperadas para su autor y los fines que perseguía de evitar más pleitos. Según informes de los curas del arzobispado, fueron los fieles quienes decidían aceptarlo o no, y cuando lo hicieron lo utilizaron e interpretaron a su favor. Algunos pueblos se decidieron por una interpretación literal del arancel; es decir, sólo pagar los rubros estipulados y no más, desconociendo prestaciones acostumbradas antes de la secularización. El mensaje de la feligresía fue claro: no aceptaría ninguna regla fija sino que se reservaba el derecho histórico de negociar, rechazar o demandar incluso a sus curas, según sus intereses. Como en otros intentos reformistas de la época, la diversidad y heterogeneidad novohispana mediatizaron los planes de las autoridades para establecer un nuevo ordenamiento.

Lorenzana viajó a Toledo en 1772 a ocupar su nueva sede, y su sucesor, Alonso Núñez de Haro y Peralta, quien gobernaría el arzobispado el resto del siglo, debió seguir permitiendo la negociación entre curas y 
fieles, o bien hacer frente a las demandas que se acentuaron en la década de 1790. El México independiente heredó toda esta problemática.

\section{Siglas}

AGI, Archivo General de Indias, Sevilla.

México, legajo 2711.

AGN, Archivo General de la Nación, México.

Bienes Nacionales ,234, exp. 3, f. 182v.

Civil, 2141, exp. 1.

AHAM, Archivo Histórico del Arzobispado de México.

CL19, libro 1.

\section{Bibliografía}

Aguirre Salvador, R. (2008)

La secularización de doctrinas en México: realidades indianas y argumentos de Madrid, 1700-1749. Hispania Sacra, 60, 122, pp. 487-505.

Aguirre Salvador, R. (2014)

El Tercer Concilio Mexicano frente al sustento del clero parroquial. Estudios de Historia Novohispana, 51, pp. 9-44.

Aguirre Salvador, R. (2015)

La diversificación de ingresos parroquiales y el régimen de sustento de los curas. Arzobispado de México, 1700-1745. Relaciones. Estudios de Historia y Sociedad, XXXVI, 142, pp. 195-235.

Aguirre Salvador, R. (coord.) (2016)

Visitas pastorales del arzobispado de México, 1715-1722. México: Universidad Nacional Autónoma de México, Instituto de Investigaciones sobre la Universidad y la Educación.

Álvarez Icaza Longoria, M.T. (2016)

Sumando fuerzas para promover cambios. Manuel Rubio y Salinas y la Junta de 1748-1749. En F. J. Cervantes Bello y M. P. Martínez López-Cano (coords.). La dimensión imperial de la Iglesia novohispana. México: Universidad Nacional Autónoma de México, Benemérita Universidad Autónoma de Puebla, pp. 309-330.

Arancel para todos los curas del arzobispado de México y unas reflexiones sobre el servicio personal de los indígenas (1840) México: reimpreso por Martín Rivera.

Brading, D.A. (1993)

Orbe indiano. De la monarquía católica a la república criolla, 14921867. México: Fondo de Cultura Económica.

Diario del Cuarto Concilio Mexicano compuesto por el doctor don Vicente Antonio de los Ríos [canónigo doctoral de Valladolid]. (1999) 
En L. Zahino Peñafort (comp.), El cardenal Lorenzana y el IV Concilio Provincial Mexicano. México: Miguel Ángel Porrúa, Universidad Nacional Autónoma de México, Universidad de Castilla-La Mancha, Cortes de Castilla-La Mancha, pp. 587-707.

Diccionario de la Lengua Española. (1984)

Madrid: Real Academia de la Lengua Española.

Escamilla González, I. (2005)

El arzobispo Lorenzana: la Ilustración en el IV concilio de la Iglesia mexicana. En M. P. Martínez López-Cano y F. J. Cervantes Bello (coords.), Los concilios provinciales en Nueva España. Reflexiones e influencias. México: Universidad Nacional Autónoma de México, Benemérita Universidad Autónoma de Puebla, pp. 123-144.

Extracto compendioso de las notas del Concilio IV Provincial Mexicano hecho y apuntado diariamente por uno de los que asistieron a él. (1999). En L. Zahino Peñafort (comp.). El cardenal Lorenzana y el IV Concilio Provincial Mexicano. México: Miguel Ángel Porrúa / Universidad Nacional Autónoma de México, Universidad de Castilla-La Mancha / Cortes de Castilla-La Mancha, pp. 294-530.

García Ayluardo, C. (2010)

Reformar la Iglesia novohispana. En C. García Ayluardo (coord.), Las reformas borbónicas, 1750-1808. México: Centro de Investigación y Docencia Económicas, Fondo de Cultura Económica, Consejo Nacional para la Cultura y las Artes, Instituto Nacional de Estudios Históricos de la Revoluciones de México, Fundación Cultural de la Ciudad de México, pp. 235-250.

Gibson, C. (1989)

Los aztecas bajo el dominio español. México: Siglo xxI.

Mazín, O. (1989)

Reorganización del clero secular novohispano en la segunda mitad del siglo XVIII. Relaciones, 39, pp. 76-78.

Gonzalbo, P. (1985)

Del tercero al cuarto Concilio Provincial mexicano, 1585-1771. Historia Mexicana, 53, 1, pp. 5-31.

Rubial García, A. et al. (2013)

La Iglesia en el México colonial. México: Instituto de Investigaciones Históricas - Universidad Nacional Autónoma de México, Benemérita Universidad Autónoma de Puebla, Ediciones de Educación y Cultura.

Sánchez Santiró, E. (2004)

El nuevo orden parroquial de la ciudad de México: población, etnia y territorio (1768-1777). Estudios de Historia Novohispana, 30, pp. 63-92. 
Taylor, W. B. (1995)

El camino de los curas y de los Borbones hacia la modernidad, en A. Matute, E. Trejo y B. Connaughton (coord.), Estado, Iglesia y sociedad en México. México: Siglo xxI, pp. 81-113.

Taylor, W. B. (1999)

Ministros de lo sagrado. Sacerdotes y fieles en el México del siglo XVIII.

Zamora: El Colegio de Michoacán, Secretaría de Gobernación, El Colegio de México.

Vetancurt, A. (1982)

Crónica de la provincia del Santo Evangelio de México. Cuarta parte del Teatro mexicano de los sucesos religiosos. México: Porrúa.

Zahino Peñafort, L. (1996)

Iglesia y sociedad en México 1765-1800. Tradición, reforma y reacciones. México: Universidad Nacional Autónoma de México.

Zahino Peñafort, L., comp. (1999)

El cardenal Lorenzana y el IV Concilio Provincial Mexicano. México:

Miguel Ángel Porrúa, Universidad Nacional Autónoma de México, Universidad de Castilla-La Mancha, Cortes de Castilla-La Mancha. 